\title{
Atypical osteochondroma of the hamate that presented clinically as carpal tunnel syndrome: report of an extremely rare case and literature review
}

Makoto Motomiya ${ }^{1,2^{*}}$, Taiki Sakazaki ${ }^{1}$ and Norimasa Iwasaki ${ }^{2}$

\begin{abstract}
Background: Osteochondroma is a benign tumor that occurs mainly at the metaphysis of long bones and seldom arises from carpal bones. We describe an extremely rare case of osteochondroma of the hamate without a typical cartilaginous cap and with a spiky bony protrusion in an elderly patient.

Case presentation: A 78-year-old right-handed female housekeeper had a multilobed osteochondroma of the hamate, which caused carpal tunnel syndrome and irritation of the flexor tendons. Radiological examinations showed a morphological abnormality of the hamate comprising a spiky bony protrusion into the carpal tunnel and a free body proximal to the pisiform. Open carpal tunnel release and resection of the spiky bony protrusion on the hook of the hamate were performed. The flexor digitorum profundus tendons of the ring and little fingers displayed synovitis and partial laceration in the carpal tunnel. Histological examination also showed atypical findings: only a few regions of cartilaginous tissue were seen in the spiky bony protrusion, whereas the free body proximal to the pisiform contained thick cartilaginous tissue such as a cartilaginous cap typical of osteochondroma. We speculated that the bony protrusion to the carpal tunnel had been eroded by mechanical irritation caused by gliding of the flexor tendon and had resulted in the protruding spiky shape with less cartilaginous tissue. The fractured cartilaginous cap had moved into the cavity within the carpal tunnel proximal to the pisiform and had become a large free body.
\end{abstract}

Conclusions: Osteochondroma of the carpal bone may take various shapes because the carpal bone is surrounded by neighboring bones and tight ligaments, which can restrict tumor growth. This type of tumor is likely to present with various symptoms because of the close proximity of important structures including nerves, tendons, and joints. The diagnosis of osteochondroma of the carpal bone may be difficult because of its rarity and atypical radiological and histological findings, such as the lack of a round cartilaginous cap. We suggest that surgeons should have a detailed understanding of this condition and should make a definitive diagnosis based on the overall findings.

Keywords: Case report, Carpal osteochondroma, Hamate, Carpal tunnel syndrome, Multilobed, Flexor tendon laceration, Elderly patient

\footnotetext{
* Correspondence: motomiya530126@yahoo.co.jp

'Department of Orthopaedic Surgery, Obihiro Kosei Hospital Hand Center|, Obihiro 080-0024, Japan

2Department of Orthopaedic Surgery, Faculty of Medicine and Graduate

School of Medicine, Hokkaido University, Sapporo 060-8638, Japan
}

C C The Author(s). 2020 Open Access This article is licensed under a Creative Commons Attribution 4.0 International License, which permits use, sharing, adaptation, distribution and reproduction in any medium or format, as long as you give appropriate credit to the original author(s) and the source, provide a link to the Creative Commons licence, and indicate if changes were made. The images or other third party material in this article are included in the article's Creative Commons licence, unless indicated otherwise in a credit line to the material. If material is not included in the article's Creative Commons licence and your intended use is not permitted by statutory regulation or exceeds the permitted use, you will need to obtain permission directly from the copyright holder. To view a copy of this licence, visit http://creativecommons.org/licenses/by/4.0/ The Creative Commons Public Domain Dedication waiver (http://creativecommons.org/publicdomain/zero/1.0/) applies to the data made available in this article, unless otherwise stated in a credit line to the data. 


\section{Background}

Osteochondroma is a benign tumor that occurs mainly at the metaphysis of long bones and is characterized by a round protrusion with a cartilaginous cap [1]. Osteochondroma of the carpal bone is extremely rare; most cases reported involved the scaphoid [2,3], and only two cases involving the hamate have been reported $[4,5]$.

Here, we describe an extremely rare case of osteochondroma of the hamate without a typical cartilaginous cap and with a spiky bony protrusion, in an elderly patient.

\section{Case presentation}

A 78-year-old right-handed female housekeeper presented to our department with pain extending from the palm to the forearm during movement of the ring and little fingers, and numbness of the median nerveinnervated area of the left hand. She had experienced intermittent pain and numbness in the hand a few years previously, and the symptoms had gradually worsened starting 1 month before her visit to our department. She had no specific medical and family history except for hypertension.

On first examination, there was tenderness along the flexor tendons of the ring and little fingers, and the range of motion of the fingers was slightly restricted because of pain. The patient had almost normal sensation in the Semmes-Weinstein monofilament test, although Tinel's sign was positive at the entrance of the carpal tunnel. Plain radiographs and computed tomography showed a morphological abnormality of the hamate and a free body proximal to the pisiform (Fig. 1a-d). The hamate had a multilobed shape with a spiky bony protrusion into the carpal tunnel and rounded bony protrusion on the dorsal-ulnar side. Magnetic resonance imaging showed that the bony protrusions were connected to the hamate body and had the same intensity as bone marrow (Fig. 1e,f).

We performed an open carpal tunnel release and resection of the spiky bony protrusion on the hook of the

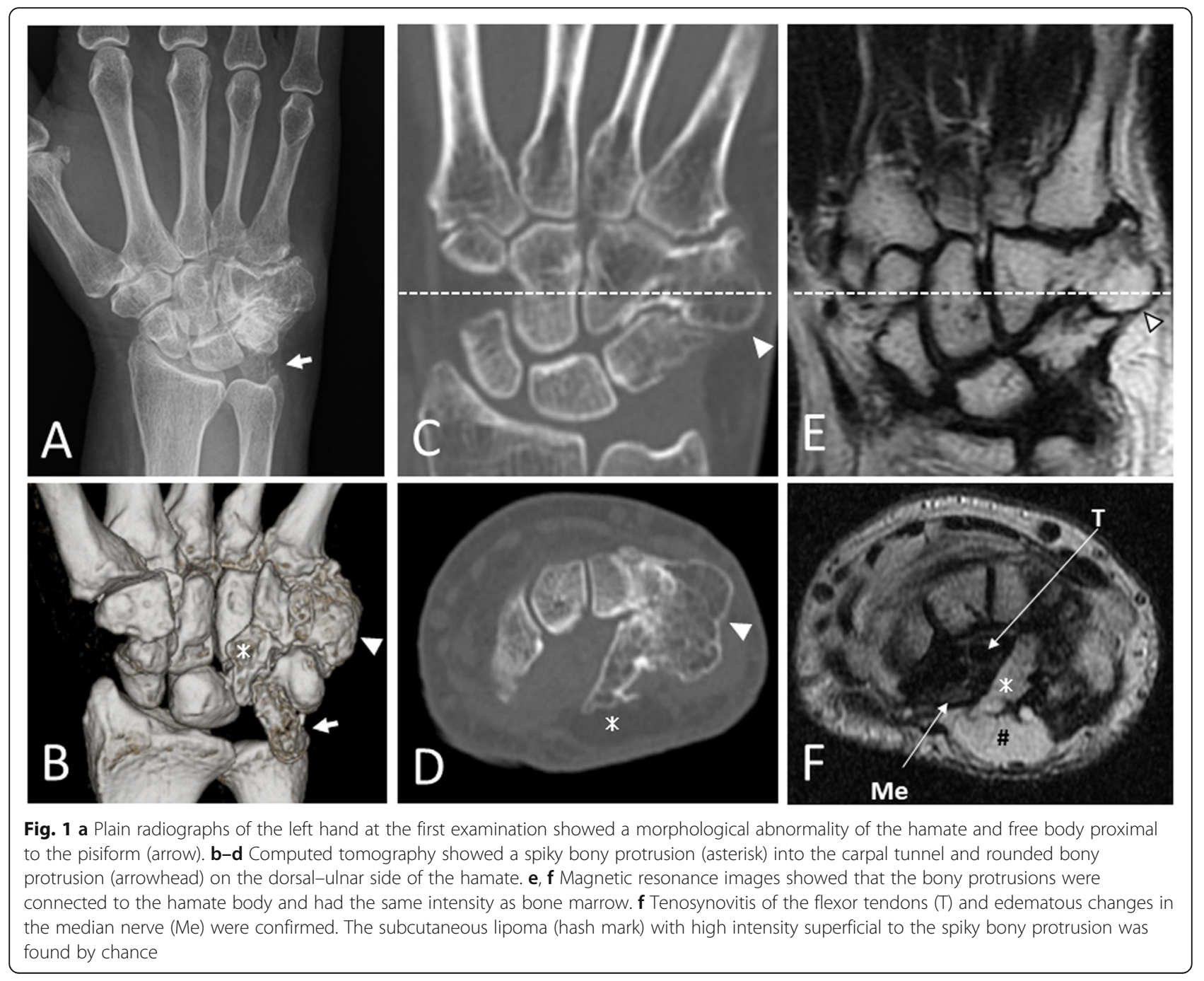


hamate with the patient under regional brachial plexus anesthesia (Fig. 2a, b). The free body proximal to the pisiform was also resected. The flexor digitorum profundus tendons of the ring and little fingers displayed synovitis and partial laceration in the carpal tunnel (Fig. 2c). After performing partial debridement of the lacerated tendons, we confirmed smooth flexor tendon gliding without irritation at the bony protrusion.

Histological examination showed only a few regions of cartilaginous tissue in the spiky bony protrusion (Fig. 3a), whereas the free body proximal to the pisiform contained thick cartilaginous tissue such as a cartilaginous cap typical of osteochondroma (Fig. 3b).

Six months after surgery, the patient displayed smooth motion of the fingers without pain and numbness. Plain radiographs and computed tomography showed no recurrence of the tumor at the resection site (Fig. $4 \mathrm{a}-\mathrm{c}$ ).

\section{Discussion and conclusion}

Osteochondroma generally originates from the metaphysis of longitudinally growing bones as the site of defects in the periosteum and/or tendon insertion [1]. Because carpal bones have a small surface of periosteum and develop from centrifugally expanding centers of ossification, osteochondroma seldom arises from carpal bones [3]. Osteochondroma in the hamate is extremely rare, and only two cases have been reported $[4,5]$. Carpal osteochondroma may take various shapes because the carpal bone is surrounded by neighboring bone and tight ligaments, which can restrict tumor growth [6].
Because the flexor retinaculum originates from the hook of the hamate, osteochondroma of the hook of the hamate can be limited by the linear growth of the flexor retinaculum and can be divided by the retinaculum, which results in a multilobed shape [5]. Of the osteochondromas noted in two previous reports, one was multilobed and the other was unilobed. These osteochondromas spread out in the dorsal-ulnar and volarulnar direction outside the flexor retinaculum because of mechanical weakness and caused slight restriction of the wrist range of motion. In our patient, the multilobed osteochondroma had spread both in the dorsal-ulnar direction and within the flexor retinaculum. To our knowledge, this is the first report of a multilobed osteochondroma in the hamate that had expanded into the carpal tunnel and caused carpal tunnel syndrome and irritation of the flexor tendons.

Osteochondroma first appears during the growth period. Symptoms related to the tumor have been reported in patients aged from their teens to around 50 years who seem to use their hand and fingers excessively [1]. A cartilaginous cap protruding into tendons and joints can be exposed to various kinds of mechanical forces such as tendon gliding and/or joint movement, which can lead to fracture and/or deformation [7]. We speculate that the bony protrusion to the carpal tunnel in our patient had been eroded by mechanical irritation caused by gliding of the flexor tendon, which had resulted in the fracture of the cartilaginous cap and the protruding spiky shape with less cartilaginous tissue. In addition, the fractured cartilaginous cap had moved into

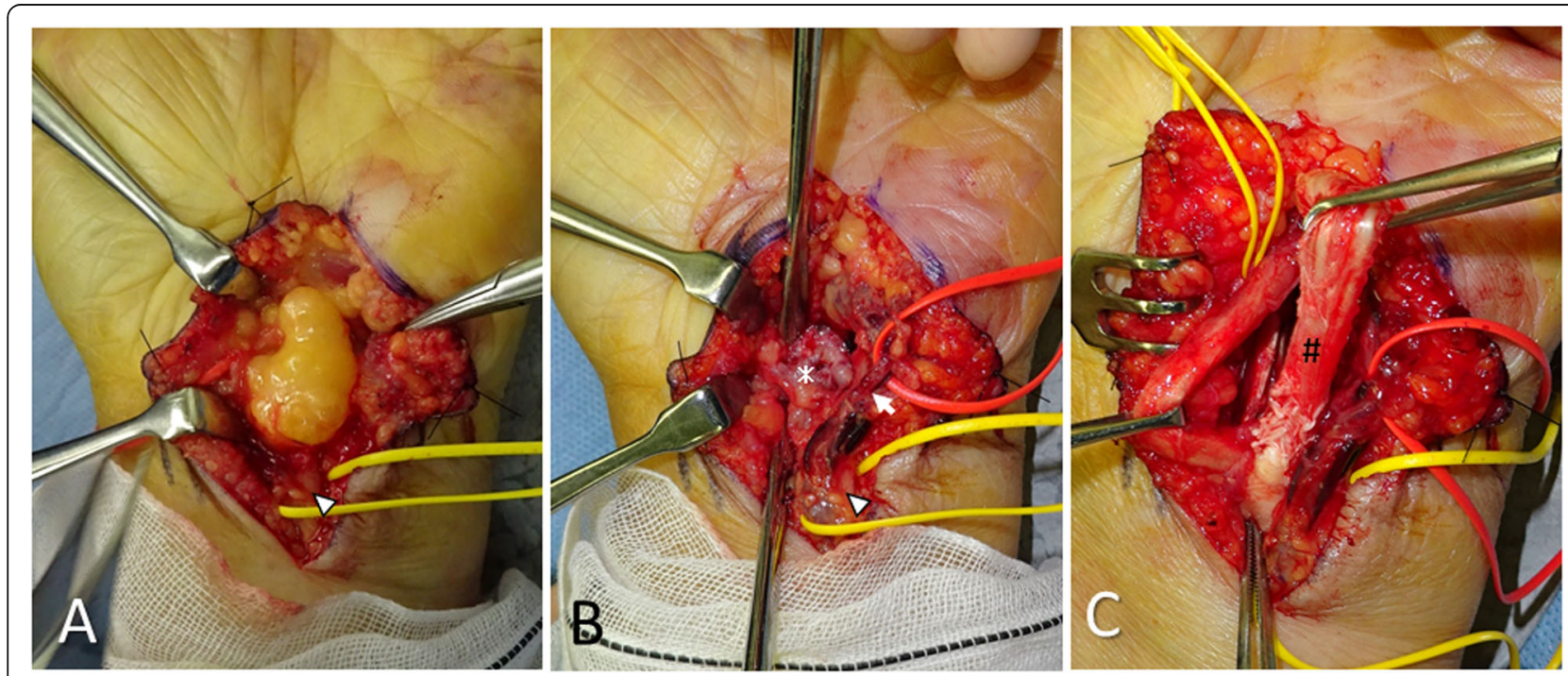

Fig. 2 Intraoperative findings. a The subcutaneous lipoma was found on the flexor retinaculum and was resected. b Open carpal tunnel release and resection of the spiky bony protrusion (asterisk) on the hook of hamate were performed after retracting the ulnar artery (arrow) and the ulnar nerve (arrowhead). c The flexor digitorum profundus tendons of the ring and little fingers (hash mark) displayed synovitis and partial laceration in the carpal tunnel 

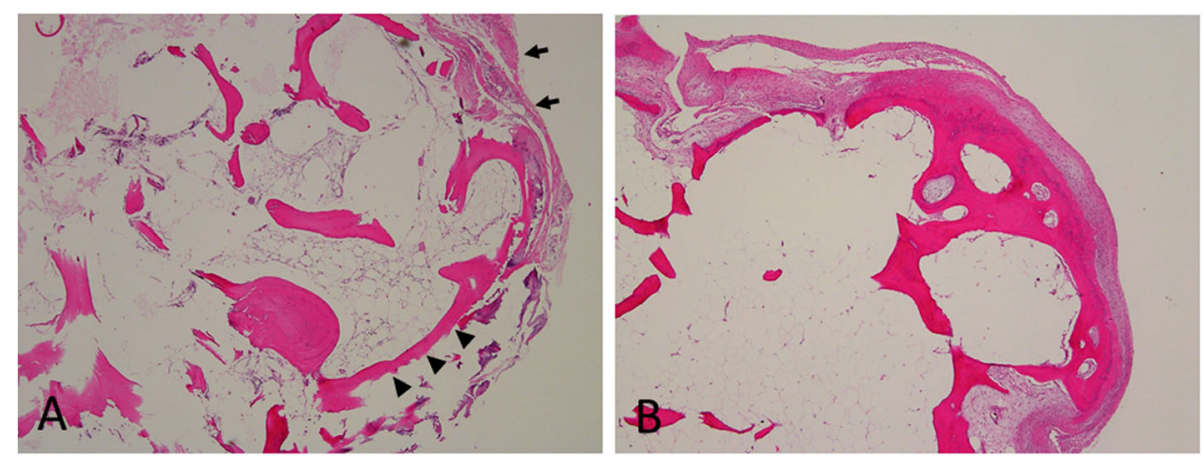

Fig. 3 a Histological images of the spiky bony protrusion showed only a few regions of cartilaginous tissue (arrows) and no hyperostotic change in the cortex (arrowheads) as in a common osteophyte. $\mathbf{b}$ Histological images of the free body proximal to the pisiform showed thick cartilaginous tissue such as the typical cartilaginous cap in the common osteochondroma. (Hematoxylin-eosin, $\times 40$ )

the cavity proximal to the pisiform and had become a large free body with thick cartilaginous tissue. By contrast, the protrusion in the dorsal-ulnar direction appeared not to have been subjected to mechanical force and had maintained a round shape. Although carpal osteochondroma has not been reported in elderly patients, it is possible that carpal osteochondromas arise because of the long-term effects of mechanical force from surrounding tissues and may show atypical forms in radiographic examination.

Osteochondroma is generally a slow growing tumor that has no pain and is treated conservatively in patients without symptoms $[1,8]$. On the other hand, osteochondroma of the carpal bone is likely to present with various symptoms, including restriction of the range of wrist motion, carpal tunnel syndrome, tendon irritation, and/or tendon rupture because of the close proximity of important structures $[6,9]$. For osteochondromas presenting with any type of symptoms, the clinician should identify and resect the responsible lesion as soon as possible. Osteochondromas can develop malignant transformation [1,3], although the malignant transformation of carpal osteochondromas has not been reported. Even if initially asymptomatic, osteochondromas of the carpal bone should be examined carefully and followed up regularly because delayed symptoms can appear as a result of long-term irritation to surrounding tissues.

Given the rarity of carpal bone tumors, the diagnosis of osteochondroma of the carpal bone can be difficult [1, 10]. Because there are bony protrusions in the palm such as the hook of hamate, it is difficult to identify a mass and/or deformity of carpal bone by palpation through the thick soft tissue of the palm. In addition, it may be difficult for radiologists and pathologists to diagnose this condition correctly, especially for cases involving atypical radiological and histological findings such as the lack of

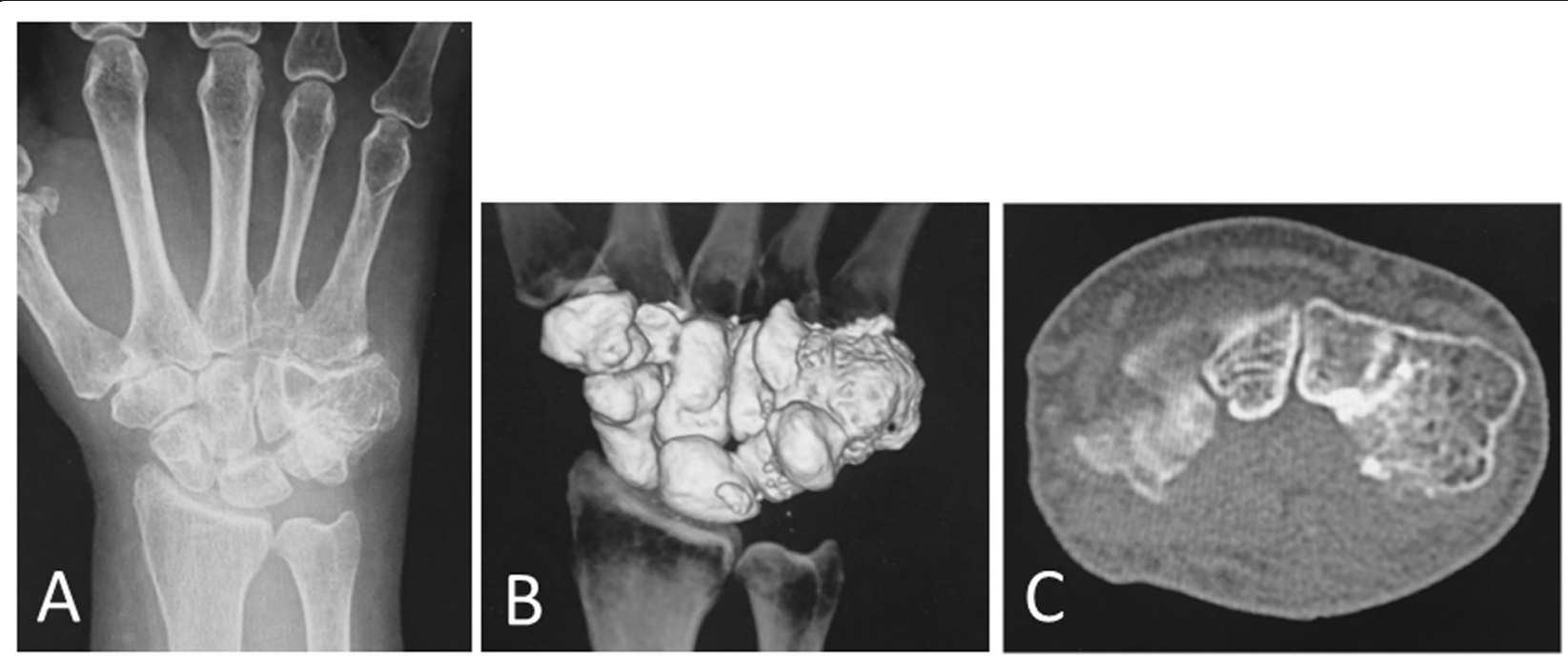

Fig. 4 Plain radiograph (a) and computed tomography images (b, c) 6 months after surgery 
a round cartilaginous cap. We suggest that surgeons should have a detailed understanding of this condition and should make a definitive diagnosis based on the overall findings.

In summary, we report a rare case of osteochondroma of the hamate with a spiky bony protrusion and without a typical cartilaginous cap because of mechanical erosion caused by gliding of the flexor tendon. An osteochondroma of the carpal bone may take various shapes because the carpal bone is surrounded by neighboring bones and tight ligaments, which can restrict tumor growth. This type of tumor is likely to present with various symptoms because of the close proximity of important structures including nerves, tendons, and joints. The diagnosis of osteochondroma of the carpal bone may be difficult because of its rarity and atypical radiological and histological findings, such as the lack of a round cartilaginous cap. We suggest that surgeons should have a detailed understanding of this condition and should make a definitive diagnosis based on the overall findings.

\section{Acknowledgements}

We thank the patient for her time, effort, and consent for this report. We are also grateful to Dr. Keisuke Kikuchi (Department of Pathology, Obihiro Kosei Hospital) for making a pathological diagnosis.

\section{Authors' contributions}

TS wrote the first draft of the manuscript and participated in the follow-up examination of the patient and clinical material. MM performed the surgery and coordinated and helped to draft and finalizes the manuscript. NI participated in the manuscript preparation, assisted with the data analysis and interpretation, and revised the manuscript for important intellectual content. All authors read and approved the final manuscript.

\section{Funding}

Not applicable.

\section{Availability of data and materials}

This is a case report of a single patient. To protect privacy and respect confidentially, no raw data have been made available in any public repository. The original operation reports, imaging studies, and outpatient clinic record are retained as per normal procedure within the medical records of our institution.

Ethics approval and consent to participate

Our institution does not require ethical approval for case reports.

\section{Consent for publication}

We confirm that the patient has given her written consent for the case report to be published.

\section{Competing interests}

The authors declare that they have no competing interests.

Received: 28 February 2020 Accepted: 7 April 2020

Published online: 13 April 2020

\section{References}

1. Murphey MD, Choi JJ, Kransdorf MJ, Flemming DJ, Gannon FH. Imaging of osteochondroma: variants and complications with radiologic-pathologic correlation. Radiographics. 2000;20:1407-34.

2. Katayama T, Ono H, Furuta K. Osteochondroma of the lunate with extensor tendons rupture of the index finger: a case report. J Hand Surg Asian Pac Vol. 2011;16:181-4
3. Uchida K, Kobayashi S, Takamura T, Yayama T, Inukai T, Baba H. Osteochondroma arising from the scaphoid. J Orthop Sci. 2007;12:381-4.

4. Cha SM, Shin HD, Kim DY. A solitary unilobed osteochondroma of the hamate: a case report. J Pediatr Orthop B. 2017;26:274-6.

5. Koti M, Honakeri SP, Thomas A. A multilobed osteochondroma of the hamate: case report. J Hand Surg Am. 2009;34:1515-7.

6. Shah NR, Wilczynski M, Gelberman R. Osteochondroma of the capitate causing rupture of the extensor digiti minimi: case report. J Hand Surg [Am]. 2009:34:46-8.

7. Carpintero P, Leon F, Zafra M, Montero M, Berral FJ. Fractures of osteochondroma during physical exercise. Am J Sports Med. 2003;31:1003-6.

8. Passanise AM, Mehlman CT, Wall EJ, Dieterle JP. Radiographic evidence of regression of a solitary osteochondroma: a report of 4 cases and a literature review. J Pediatr Orthop. 2011;31:312-6.

9. Takagi T, Matsumura T, Shiraishi T. Lunate osteochondroma: a case report. J Hand Surg [Am]. 2005;30:693-5.

10. Anantavorasakul N, Uerpairojkit C, Leechavengvongs S. Painful snapping of thumb caused by Osteochondroma of trapezium. J Hand Surg Asian Pac Vol. 2017;22:255-8.

\section{Publisher's Note}

Springer Nature remains neutral with regard to jurisdictional claims in published maps and institutional affiliations.
Ready to submit your research? Choose BMC and benefit from:
- fast, convenient online submission
- thorough peer review by experienced researchers in your field
- rapid publication on acceptance
- support for research data, including large and complex data types
- gold Open Access which fosters wider collaboration and increased citations
- maximum visibility for your research: over $100 \mathrm{M}$ website views per year
At BMC, research is always in progress.
Learn more biomedcentral.com/submissions 